\title{
O jogo "remo da saúde bucal" como ferramenta para educação em saúde bucal
}

\author{
The game "oral health rowing" as a tool for oral health education \\ El juego "remo de salud bucal" como herramienta para la educación en salud buccal
}

Tamiris Faro Casseb ${ }^{1 *}$, Liliane Silva do Nascimento², Pettra Blanco Lira Matos², Adalberto Lírio de Nazaré Lopes ${ }^{2}$, Andréa Cristina Marassi Lucas², Mariana Jessica Mafra Pires ${ }^{1}$, Alessandra dos Santos Tavares Vieira1, Rosana Nazaré Leão Souza², Sâmela Stefane Correa Galvão², Isabella Oliveira dos Santos ${ }^{1}$.

\section{RESUMO}

Objetivo: Desenvolver um jogo de tabuleiro nomeado "O remo da saúde bucal" e utilizá-lo como tecnologia para promoção da saúde. Métodos: Trata-se de pesquisa-ação com abordagem qualitativa. O estudo ocorreu no local de treinamento dos atletas de uma cidade do Pará. Foram realizados cinco encontros com média de quinze atletas em cada encontro. Utilizou-se rodas de conversa semanais e aplicação do jogo como estratégia de promoção da saúde. Durante as rodadas foi possível observar o crescimento do conhecimento dos jogadores, os participantes foram divididos em dois grupos, em cada rodada um representante de cada time jogava o dado e percorria o tabuleiro de acordo com o resultado, o objetivo era chegar primeiro na última casa. Resultados: Durante a prática lúdica com a execução do jogo eram realizadas perguntas sobre os temas abordados nas rodas de conversa anteriores. O jogo demonstrou ter grande aceitação pelos participantes, durante a realização da atividade todos se mostraram participativos e competitivos, buscando responder corretamente as perguntas e vibrando a cada jogada, a ferreamente instigou-os à competição e à aprendizagem. Conclusão: $O$ jogo de tabuleiro contribuiu na construção do conhecimento através da ludicidade, tornando-se importante ferramenta para educação em saúde bucal.

Palavras-chave: Odontologia comunitária, Promoção da saúde, Jogos e brinquedos.

\begin{abstract}
Objective: To develop a board game named "The paddle of oral health" and use it as a technology for health promotion. Methodology: This is action research with a qualitative approach. The study took place at the training site of athletes in a city in Pará. Five meetings were held with an average of 15 athletes in each meeting. Conversation circles were used on Saturdays and the game was used as a health promotion strategy. During the rounds it was possible to observe the growth in the knowledge of the players, the participants were divided into two groups, in each round a representative of each team played the dice and crossed the board according to the result, the goal was to reach the last house first . Results: During the execution of the game, questions were asked about the topics covered in the previous conversation circles. The game showed great acceptance by the participants, during the activity everyone was participatory and competitive, seeking to answer questions correctly and vibrating with each move, and ironically instigated them to competition and learning.Conclusion: The board game contributed to the construction of knowledge through playfulness, becoming an important tool for education in oral health.
\end{abstract}

Key words: Community dentistry, Health promotion, Play and playthings.

1Universidade do Estado do Pará (UEPA), Belém - PA. *E-mail: tfc_93@hotmail.com

¿Universidade Federal do Pará (UFPA), Belém - PA.

SUBMETIDO EM: 2/2020

ACEITO EM: 3/2020

PUBLICADO EM: 6/2020 


\section{RESUMEN}

Objetivo: Desarrollar un juego de mesa llamado "La paleta de la salud oral" y utilizarlo como tecnología para la promoción de la salud. Métodos: Esta es una investigación de acción con un enfoque cualitativo. El estudio se realizó en el sitio de entrenamiento de atletas en una ciudad de Pará. Se realizaron cinco reuniones con un promedio de 15 atletas en cada reunión. Los sábados se usaban círculos de conversación y el juego se usaba como estrategia de promoción de la salud. Durante las rondas fue posible observar el crecimiento en el conocimiento de los jugadores, los participantes se dividieron en dos grupos, en cada ronda un representante de cada equipo jugó los dados y cruzó el tablero de acuerdo con el resultado, el objetivo era llegar primero a la última casa. Resultados: Durante la ejecución del juego, se hicieron preguntas sobre los temas tratados en los círculos de conversación anteriores. El juego mostró una gran aceptación por parte de los participantes, durante la actividad todos fueron participativos y competitivos, buscando responder preguntas correctamente y vibrando con cada movimiento, e irónicamente los instigó a la competencia y al aprendizaje. Conclusión: El juego de mesa contribuyó a la construcción del conocimiento a través del juego, convirtiéndose en una herramienta importante para la educación en salud oral.

Palabras clave: Odontología comunitaria, Promoción de la salud, Juegos y juguetes.

\section{INTRODUÇÃO}

O esporte vem como uma proposta inclusiva as classes vulneráveis, por se tratar de um fenômeno sociocultural presente na vida das pessoas, possibilita a inclusão em ambientes controlados, estimuladores e educativos, de grupos como jovens que poderiam estar nas drogas, nas ruas ou em carreira na delinquência. O esporte possui potência de contribuição para o estímulo e desenvolvimento de uma cidadania ativa e responsável (RODRIGUES HA, et al., 2013; VIANNA JA e LOVISOLO HR, 2009; AZEVEDO MAO e FILHO GA, 2011).

Nesse âmbito, a vulnerabilidade social se mostra como um elemento marcante na realidade social latinoamericana do final dos anos 1990, se tornando cada vez mais evidente devido ao fato de que as condições de pobreza e concentração de renda aumentaram gradativamente nos países subdesenvolvidos; o que vem refletir no aumento da instabilidade para grande parte dos habitantes desfavorecidos desses países. Então, o esporte vem como uma atividade alternativa dominante à rua, possibilitando um futuro através do exercício (OLIVEIRA RC, 2017; VIANNA JAVM e LOVISOLO HR, 2011).

A Odontologia desportiva é uma área que objetiva promover saúde e rendimento físico ideais para os atletas, além de intervir em doenças da cavidade oral que possam comprometer o desenvolvimento da atividade física. A literatura mostra que o excesso de treino, a necessidade do equilíbrio hídrico, a dieta, entre outros fatores que fazem parte da vida do atleta possuem consequências na cavidade bucal. Em, 2013 foi fundada a Academia Brasileira de Odontologia do esporte (Abroe), que promove a odontologia no esporte. (SILVA AMG e BONIS R, 2018; PASTORE GU, et al., 2016; ASSIS C, 2013).

A saúde bucal como parte integrante e inseparável da saúde geral do indivíduo está diretamente relacionada a riscos de disseminações sistêmicas de bactérias com consequente diminuição do rendimento físico em atletas, por isso é imprescindível a divulgação no meio esportivo, acerca da importância da manutenção da saúde bucal.

A educação em saúde se apresenta como ferramenta mais poderosa para se evitar as doenças orais, pois a falta de informação sobre os cuidados adequados de higiene leva a doenças na cavidade oral, apesar dessas informações estarem disponíveis na mídia, não consegue atingir de forma adequada todas as pessoas, levando em consideração a classe socioeconômica, portanto os informes corretos e atividades que estimulem o aprendizado o sujeito tem a possibilidade de adquirir hábitos para a promoção, recuperação e manutenção da própria saúde oral. A educação e a informação sobre os cuidados com a saúde bucal têm sido salientadas como elementos eficientes para mudança de hábitos (ALVES DCB, et al., 2017; PAULETO ARC, et al., 2004; SOUSA RHA, et al., 2017). 
No campo de procedimentos de aprendizagem, entende-se o Letramento Funcional em Saúde (LFS) como a habilidade de entender, interpretar e utilizar as informações sobre saúde; de maneira, que a informação seja repassada de forma adequada tanto para pessoas com nível de letramento satisfatório quanto para pessoas com letramento limitado. Devido a sua essência interdisciplinar, os sistemas de saúde/educacional entre outros fatores influenciam no aprendizado das informações (PASSAMAI MPB, et al., 2012).

O lúdico é uma característica inerente ao ser humano, por meio do qual pode-se construir uma aprendizagem significativa. Salientando que apesar do jogo ser uma atividade paradoxal: ao mesmo tempo livre, espontânea e regrada, os ensinamentos adquiridos pela ferramenta podem se constituir novas atitudes de prevenção, desde que suas ações estejam associadas às políticas socioeconômicas e ambientais favoráveis a mudança (GEHLEN SM, 2013; MIRANDA TG e GALVAO TA, 2012; CARVALHO EFF e BRAGA PET, 2013; TOSCANI NV, et al., 2007).

Em um universo onde a inclusão social é realizada pelo esporte e por meio dele os atletas são ensinados valores como cidadania, solidariedade, entre outros, buscou-se realizar um projeto sobre saúde bucal com um público que vive em condições de vulnerabilidade social e como consequência não tem acesso a todas as informações adequadas para os cuidados corretos com a saúde, por meio de tecnologias ativas, sendo uma delas o jogo de tabuleiro.

Nesse sentido, o jogo apresenta-se como uma atividade valiosa e efetiva que utiliza o lúdico, intelectual, afetivo, didática, dotado de uma dinâmica que vem estimular a interação social, promovendo a aprendizagem e o LFS. Objetivou-se desenvolver um jogo de tabuleiro para uso como tecnologia em saúde bucal para promoção de saúde com atletas do remo olímpico.

\section{MÉTODOS}

Trata-se de pesquisa-ação com abordagem qualitativa. $O$ estudo ocorreu no local de treinamento dos atletas de uma cidade do Pará. Foram realizados cinco encontros com média de 15 atletas em cada encontro. Utilizou-se rodas de conversa e aplicação do jogo como estratégia de promoção da saúde. Durante o jogo foi possível observar o crescimento do conhecimento dos jogadores, os participantes foram divididos em dois grupos, em cada rodada um representante de cada time jogava o dado e percorria o tabuleiro de acordo com o resultado, o objetivo era chegar primeiro na última casa.

Os atletas foram escolhidos através de um convite e após conhecimento da realidade local e percepção sobre a vulnerabilidade social na qual os participantes se encontravam aconteceram reuniões com os responsáveis pela associação para explicar o projeto. Os encontros tiveram intervalos mensais com a escolha de atividade no sábado, com o intuito de contemplar todos os atletas que estavam matriculados na associação de remo, sem atrapalhar o horário escolar, já que alguns alunos estudavam pela parte da manhã e outros pela tarde. A pesquisa ocorreu no período de 25 de agosto de 2018 a 12 de janeiro de 2019.

Durante os encontros foram realizadas rodas de conversas abordando os seguintes temas: Cárie e alimentação saudável, doença periodontal, higienização correta da cavidade oral e câncer bucal, sendo um tema por semana, o objetivo dessa atividade foi promover um diálogo sobre os assuntos, permitindo que todos que estivessem presentes se sentissem a vontade pra se expressar.

Ao final das atividades, foram realizadas dinâmicas como estratégia de reforçar o que havia sido explicado, as dinâmicas utilizadas foram: dinâmica da canoa, um exercício de apresentação onde os jovens faziam uma canoa com papel e escreviam seu nome, quanto tempo praticava o esporte e o que motivava a remar. Dinâmica dos alimentos, onde vários alimentos foram colocados sobre a mesa, foram realizadas perguntas e as respostas eram os alimentos. Dinâmica da escovação, foram doados kits de higiene oral, em seguida, com a ajuda de um macro modelo foi ensinado como realizar a higienização bucal correta e em seguida foi executada a escovação supervisionada com o intuito de verificar se haviam aprendido os movimentos e corrigir qualquer dúvida que persistisse durante a escovação .

O jogo foi desenvolvido por técnica construtiva a partir dos resultados das rodas de conversa que proporcionaram um diálogo aberto, possibilitando troca de informações e respostas das dúvidas dos 
presentes, após observação das perguntas mais frequentes durante todos os encontros, foram elaboradas as perguntas para o jogo buscando eliminar qualquer incerteza que tenha ficado sobre os assuntos.

O jogo de tabuleiro foi utilizado no último dia para promoção de saúde bucal intitulado "Remo da saúde bucal" abordando com perguntas todos os assuntos que foram citados nas rodas de conversas anteriores, permitindo assim avaliar o aprendizado dos atletas durantes as atividades. Os participantes foram divididos em duas equipes, os dois grupos possuíam o mesmo número de pessoas, a cada rodada um atleta jogava 0 dado, de acordo com o resultado movia-se o pino pelo tabuleiro.

O jogo de tabuleiro foi composto por 28 casas, cada casa correspondia um tipo de situação, casas que estavam apenas numeradas para dar continuidade ao jogo, outras com comandos, elementos de sorte ou azar, casas com perguntas e as casas denominadas "barco" que significavam uma pergunta sobre os temas abordados nas rodas de conversa anteriormente realizadas.

O grupo vencedor era aquele que chegasse primeiro na última casa. A pesquisa foi submetida ao Comitê de Ética do Instituto de Ciências da saúde da Universidade Federal do Pará- ICS/UFPA e aprovada sob o número 1.659.973. Foram entregues e explicados aos participantes e seus repensáveis os seguintes termos: Termo de consentimento livre e esclarecido (TCLE) e o Termo de assentimento Livre e esclarecido (TALE), todos os envolvidos assinaram duas cópias, ficando uma com as pesquisadoras e a outra com o responsável.

\section{RESULTADOS}

O jogo foi aplicável aos adolescentes, os quais, correspondem a uma fração da população que influencia os resultados globais de saúde pública. A adolescência é um momento de formação de hábitos e estilo de vida, é um período crítico, necessitando de uma atenção especial, pelo fato de ser uma fase de transição da infância para a juventude, é um momento de busca pelo equilíbrio psicológico, questões como vulnerabilidade social, determinantes sociais afetam a construção do autocuidado (BRITO SR, et al., 2016).

O design do jogo foi elaborado com o fundo da imagem do mar para familiarizar o jogo para a realidade dos remadores, a impressão foi feita em papel couché, em tamanho A3. Participaram do estudo 34 jovens da Associação de Remo do Guajará, localizada no município de Belém, no estado do Pará. O sexo masculino predomina com 27 meninos e 7 meninas, totalizando 34 jovens, com idade entre 09 a 26 anos, todos participam regularmente dos treinos na associação, sendo a maioria estudantes de escolas públicas do município, o grau de escolaridade varia entre o ensino fundamental até o ensino superior.

A Associação de remo preza pela educação dos esportistas, desse modo só podem frequentar os treinos os alunos que estiverem com a frequência e média escolar apropriada, para comprovar as informações os jovens entregam os seus boletins aos responsáveis do projeto. Antes do início da competição foi explicado aos jovens como o jogo iria acontecer, suas regras e seus objetivos, enfatizando a importância de se manter uma higiene saudável e assim obter uma qualidade na saúde bucal, com ênfase na promoção da saúde.

Há que se destacar que, todos os componentes do jogo educativo planejado pelas pesquisadoras fazem menção a promoção de saúde bucal sobre temas abordados anteriormente nas rodas de conversa, (as perguntas foram elaboradas com uma linguagem simples e de fácil compreensão), sempre buscando sanar dúvidas que os atletas pudessem vir a ter. Nesse universo, o lúdico torna-se um recurso pedagógico imprescindível a ser abordado nas atividades, devido a brincadeira enquanto componente do cotidiano, desperta o interesse do participante, que o torna sujeito ativo e empoderado do processo de construção do conhecimento.

Dessa maneira, o processo de aprendizagem se dá de uma forma agradável e motivadora, o que orientou a elaboração do jogo de tabuleiro com temas sobre saúde bucal, conforme mostra o Quadro 1, o design do jogo foi elaborado com o fundo do mar para aproximar o tabuleiro ao cotidiano dos atletas, apresentado na Figura 1 (RAUL MCTD, 2007).

Após a aplicação do jogo foi entregue aos participantes papel e caneta e feita a orientação para que escrevessem no papel o que haviam aprendido com a atividade desenvolvida, o tempo disponibilizado para essa atividade foi de 30 minutos. Alguns atletas preferiram desenhar, outros escrever ou até mesmo fazer 
anotações com desenhos e caligrafia. A representatividade do desenho vem em função da dificuldade da escrita devido à baixa escolaridade de alguns participantes. No desenho a forma de comunicação é mais espontânea, através dele pode-se notar a vivência de um aprendizado cultural e ambiental. (COMPARINI IP, 2016).

O jogo de tabuleiro obteve grande aceitação por parte dos jovens que foram o alvo da pesquisa, observouse a expectativa e competitividade que o jogo gerou entre as equipes participantes, durante a partida todos se empenhavam em acertar as respostas e quando havia uma resposta incompleta, os participantes da equipe adversária completavam corretamente o que fora perguntado, destacando que não ocorreu uma resposta incorreta durante a partida, demonstrando assim que os participantes haviam aprendido sobre 0 assunto.

Figura 1 - Jogo de tabuleiro elaborado pelas pesquisadoras, nomeado de "remo da saúde bucal", Belém PA, outubro de 2019.

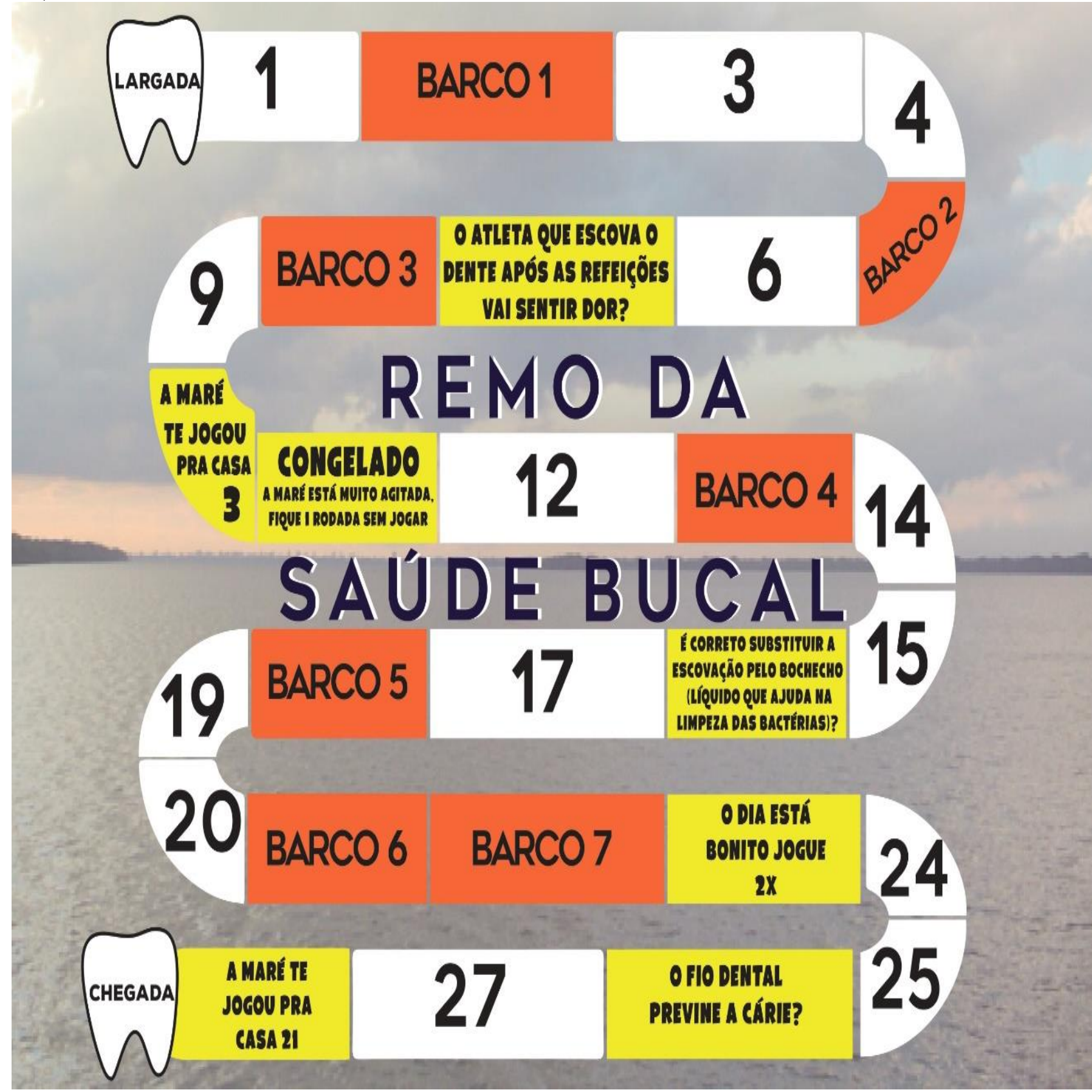

Fonte: Casseb TF, et al., 2019. 
Quadro 1 - Tabela sobre as regras do jogo de tabuleiro "remo da saúde bucal" utilizado com os atletas do remo. Belém-Pará, outubro de 2019.

\begin{tabular}{|c|c|}
\hline Regras & Jogo: O Remo da saúde bucal \\
\hline O jogo & $\begin{array}{l}\text { O jogo é composto por } 28 \text { casas. Os assuntos abordados são: cárie; higienização } \\
\text { bucal correta; alimentos cariogênicos; doença periodontal e câncer bucal. A dinâmica } \\
\text { do jogo consiste em andar pelo tabuleiro, movendo as peças de acordo com a } \\
\text { indicação dos dados, passando por casas contendo perguntas e armadilhas. } \\
\text { A partir das perguntas contemplando os temas sobre saúde bucal, consegue-se } \\
\text { avaliar o nível de aprendizagem, que obtiveram os atletas durante as rodas de } \\
\text { conversas, além de sanar possíveis dúvidas que ainda persistirem sobre os temas. }\end{array}$ \\
\hline $\begin{array}{l}\text { Assuntos } \\
\text { abordados }\end{array}$ & $\begin{array}{l}\text {-Cárie e Alimentação Saudável- uma das doenças bucais mais prevalentes. Devido a } \\
\text { alimentação ser um fator influente na doença, os assuntos foram inter-relacionados } \\
\text { nas rodas de conversa. } \\
\text {-Doença periodontal- uma das doenças bucais mais prevalentes, além de ter sido um } \\
\text { dos temas mais frequentes nas dúvidas dos participantes. } \\
\text {-Higienização correta da cavidade oral- Com a finalidade de instruir os participantes a } \\
\text { aprenderem a manter a saúde bucal. } \\
\text {-Câncer bucal- Devido a grande exposição dos atletas ao sol durante os treinos e } \\
\text { competições o assunto torna-se de fundamental importância. }\end{array}$ \\
\hline Componentes & 01 Tabuleiro, 01 Dado, 02 Pinos, 10 cartinhas com perguntas \\
\hline Objetivo do jogo & Ser o primeiro grupo a chegar na casa escrito "chegada" no tabuleiro. \\
\hline Como jogar & $\begin{array}{l}\text { 1- Os atletas foram divididos em dois grupos com quantidades iguais. } \\
\text { 2- Após a divisão foi verificado através de par ou ímpar quem seria o primeiro jogador. } \\
\text { Para iniciar o jogo joga-se o dado e de acordo com a numeração que cair anda-se com } \\
\text { o "peão" até a casa correspondente. } \\
\text { 3- Cada casa possui uma finalidade, caso ele caia em uma casa escrito "barco" o } \\
\text { mediador fará uma pergunta sobre os assuntos abordados durante a roda de conversa } \\
\text { (foram elaboradas } 20 \text { questões sobre os assuntos), se o grupo acertar continua } \\
\text { jogando, se errar fica uma rodada sem jogar. Existem algumas casas "armadilhas" } \\
\text { para deixar o jogo ainda mais competitivo. }\end{array}$ \\
\hline Regras & $\begin{array}{l}\text { Necessário no mínimo de dois jogadores. } \\
\text { Possui três tipos de casa: } \\
\text { 1- Casa "barco": indica uma pergunta, caso o jogador ou grupo não acerte a pergunta, } \\
\text { fica-se uma rodada sem jogar. } \\
\text { 2- Casa com comandos: que são armadilhas, cada uma tem um tipo de comando. } \\
\text { 3- Casa com perguntas: caso o jogador ou grupo não acerte a resposta da pergunta } \\
\text { fica uma rodada sem jogar. } \\
\text { 4- Casa numeradas: para dar continuidade no jogo. } \\
\text { 5- Casa Início e chegada: marcam o começo da competição e o término. }\end{array}$ \\
\hline Público-alvo & Os atletas do remo, porém pode ser aplicado com outros públicos. \\
\hline Duração do jogo & 2( \\
\hline
\end{tabular}

Fonte: Casseb TF, et al., 2019. 
O jogo permitiu realizar uma avaliação coletiva do aprendizado dos participantes, porém as anotações entregues pelos participantes permitiram mensurar o conhecimento individual. $\mathrm{Na}$ maioria dos papéis verificou-se que os assuntos mais abordados foram a cárie, escovação dentária (higiene bucal), alimentação, essas temáticas geraram bastante dúvidas e relatos de experiências durante a roda de conversa, como representado na Figura 3.

Figura 3 - Quadro avaliativo elaborado por três participantes após a partida do jogo de tabuleiro. Na figura A a atleta descreve suas memórias sobre os assuntos abordados durante o jogo. Já na figura $B$ representa a importância da orientação da escovação. Na figura C o participante escreveu e desenhou o que aprendeu com a atividade

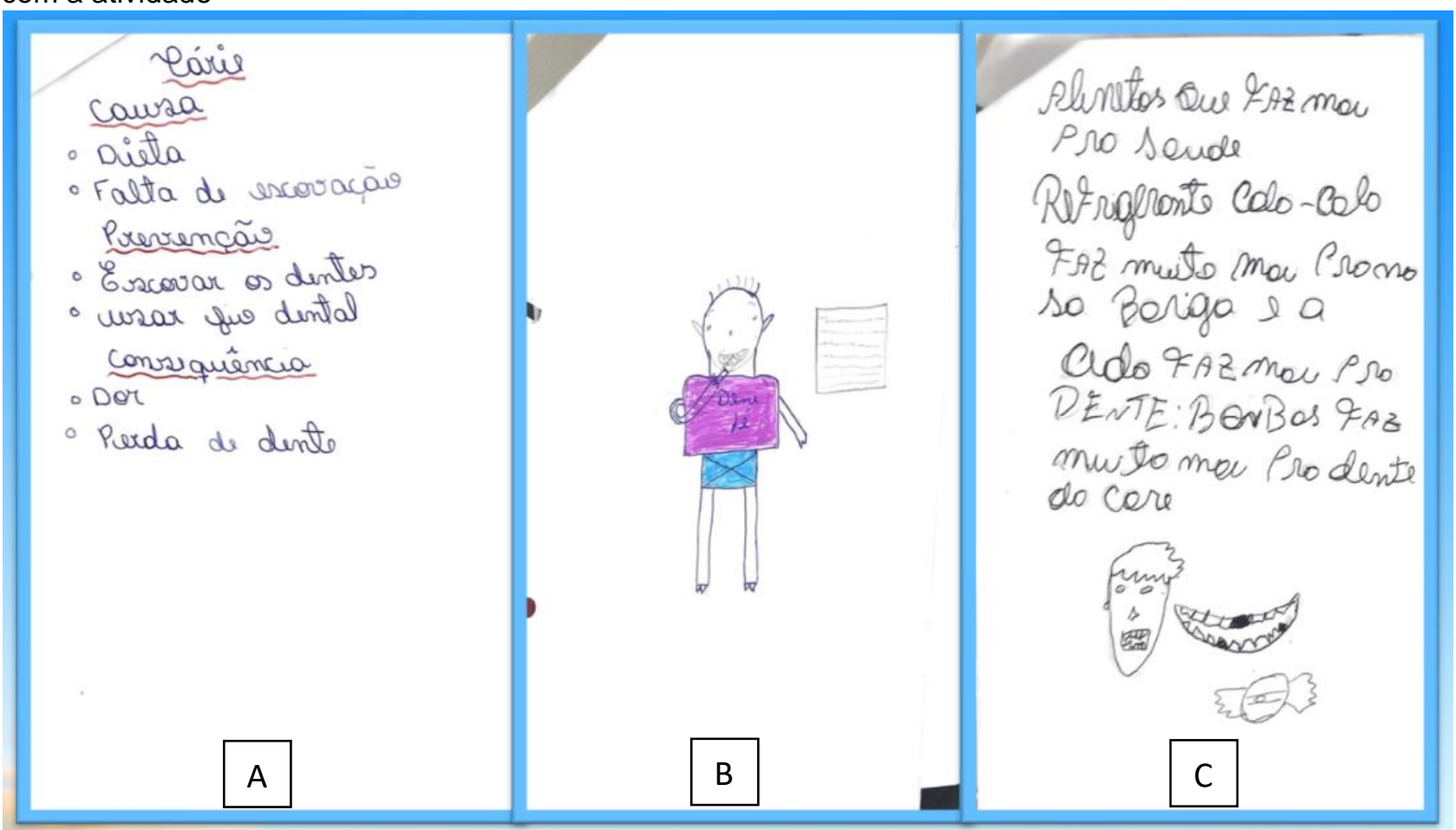

Fonte: Casseb TF, et al., 2020.

Após a análise dos relatos dos participantes notou-se que o objetivo da pesquisa foi atingido, na maioria das anotações os atletas se expressavam através da escrita ou desenho, com conteúdos que foram abordados durantes os encontros, mas com um olhar individual, pois nesse momento conseguiram destacar o que aprenderam e sinalizar o que mais chamou sua atenção. Desse modo o jogo torna-se um importante recurso metodológico de educação em saúde.

A utilização de jogos lúdicos constitui um dispositivo acessível, devido ao baixo custo. A partida permitiu que o assunto fosse reforçado e assim fixado de uma forma prazerosa, além de estimular o comportamento de cooperatividade entre os jogadores das equipes, pois para jogar os dados as equipes entravam em consenso para escolher o jogador da vez, quando o pino caia em uma casa de pergunta todos entravam em acordo para responder, as vezes até mesmo os jogadores da equipe adversaria queriam responder a pergunta da outra equipe para mostrar que já sabiam a resposta, mostrando ter gerado entusiasmo, vontade de participação dos presentes e aprendizado dos jovens durante a pesquisa (RODRIGUES DA, et al., 2015).

\section{DISCUSSÃO}

Nessa fase a higiene oral é negligenciada, além de outros fatores como a dieta deficiente, tornam a cavidade oral um ambiente mais propicio para a cárie e outras doenças bucais. Nesse período a ausência de higiene oral adequada também é causada pela falta de instrução e informação correta que leva a comportamentos prejudiciais e nocivos para a saúde, porém só informar não é o suficiente para mudar hábitos, é necessária uma relação dialogal, em que os participantes possam estar envolvidos em todos os 
momentos das ações educativas, por isso a educação em saúde deve ser realizada com metodologias onde o sujeito se torne responsável pela sua saúde (TSUZUKI FM, et al., 2018).

Pensando nesse público, buscou-se realizar ações de educação em saúde bucal, com intuito de causar mudanças efetivas na saúde. Por tanto, instruções e orientações correta sobre saúde bucal, por meio de ações educativas para promoção de saúde, tornam-se fundamentais para evitar futuras doenças orais, a pesquisa mostrou que após as primeiras informações repassadas os participantes se sentiram estimulados a buscarem mais conhecimentos sobre o assunto, através de questionamentos e compartilhamento de experiências, tornando um momento prazeroso de diálogo e troca de informações (TOMITA NE, et al., 2001; FADEL CB, et al., 2013).

A educação em saúde se constitui em um processo participativo de construção de conhecimento que permite o desenvolvimento de habilidades para perceber, analisar e resolver problemas. Se faz necessária para evitar e/ou retardar o processo saúde-doença. As participações dos atletas nas atividades desenvolvidas foram importantes para a construção do conhecimento, não ocorreu recusa de participação durantes os encontros, podendo assim ocorrer um compartilhamento de ensinamentos nas dinâmicas, entre os jovens e as pesquisadoras gerando um resultado positivo para a pesquisa (SEBOLD R, 2017; SALCI MA, et al., 2013).

É importante destacar que, a educação é um instrumento eficiente no processo de transformação social, pode-se promover por meio da ação educativa, mudanças significativas, no modo de agir dos sujeitos, ajudando assim a desenvolver um pensamento crítico e reflexivo sobre o autocuidado, melhorando a qualidade de vida e bem-estar, tornando-se assim uma ferramenta importante para a promoção da saúde. Os participantes relataram que já estavam utilizando seus novos conhecimentos em casa e ensinando os parentes as formas corretas de higienização da cavidade oral e outros cuidados com a saúde bucal, foi informado por um deles que entendia que esse também era um papel dele como esportista (BOERI ZA, 2013; FALKENBERG MB, et al., 2014).

A promoção em saúde bucal abrange um nível complexo, devido à variedade de contextos e intervenções possíveis. O que exige permanente mudança de estratégias e métodos, para impactar seus efeitos a longo prazo, alterando positivamente comportamentos e hábitos, o método utilizado mostrou-se eficaz, pois conseguiu segurar a atenção dos adolescentes para os assuntos abordados de uma forma leve e descontraída. Por meio de ações de promoção da saúde pode-se captar o indivíduo e ensiná-lo a melhorar a própria saúde, tornando-o empoderado, possibilitando a transformação desse sujeito, em ator principal do autocuidado (KUSMA SZ, et al., 2012; BUSS PM, 2002).

A aprendizagem é o meio que são adquiridos conhecimentos, valores, competências, o jogo determina situações que ensinam os jogadores a lidarem com conflitos e assim buscarem soluções para o problema encontrado, verificou-se a habilidade dos participantes para buscarem as respostas das perguntas realizadas na atividade. A competição no jogo estimula a auto avaliação dos participantes sobre suas habilidades e conhecimentos, além de promover a cooperação durante a partida, os indivíduos conseguem trocar informações durante a brincadeira, tornando o aprendizado prazeroso, entre risos e falas com o time adversário pode se notar a competitividade entre as equipes. $O$ jogo é gerador de cultura, além de ser uma estratégia importante e prazerosa para realizar a promoção de saúde bucal (PRADO LL, 2018).

Nessa perspectiva de ensino, percebeu-se a necessidade de utilizar uma tecnologia atrativa para os jovens, como ferramenta para entreter e estimular o ensino, devido ao fato dos adolescentes não terem acesso com facilidade a internet, utilizou-se o jogo de tabuleiro que não necessita de recursos digitais e possibilita estimular a aprendizagem, competitividade e cooperatividade ao mesmo tempo, permitindo o aprendizado não só do assunto abordado, mas lições de cidadania, sendo a educação é fundamental para a formação cidadã (SILVA CGCO e CARDOSO FS, 2018).

O jogo permite a prática de atitudes sociais para convivência com o próximo como respeito, solidariedade, cooperação, obediência às regras, responsabilidade, iniciativa pessoal e grupal, auxiliam na simulação de valores de cidadania, o que também é instruído no esporte, permitindo assim ressaltar e colocar em prática ainda mais os valores ensinados (OLIVEIRA VLS, 2011; SILVA NMA, et al., 2016). 


\section{CONCLUSÃO}

Conclui-se que o jogo de tabuleiro intitulado "Remo da saúde bucal" é eficaz para promoção da saúde, atingindo amplamente o objetivo de realizar mudanças de atitudes em relação a saúde bucal dos atletas do remo. $O$ aspecto lúdico do jogo permitiu que esses atores conseguissem se sentir estimulados e assim compreenderem naturalmente os assuntos abordados durantes as rodas de conversas e o jogo. A aprovação dos participantes com o entretenimento provou a eficácia dessa estratégia educativa, como uma tecnologia adicional a ser utilizada como ferramenta de educação em saúde, mostrando que a atividade proporciona uma aprendizagem lúdica e acessível a todos os públicos estimulando a aquisição do conhecimento por meio da diversão.

\section{REFERÊNCIAS}

1. ALVES DCB, et al. Odontologia no esporte: conhecimento e hábitos dos atletas do futebol e basquetebol sobre saúde bucal. São Paulo, Rev Bras Med Esporte [online], 2017; 23: 407-411.

2. ASSIS C. Os rumos da odontologia do esporte no Brasil. Revista Brasileira Odontologia, 2013,70: 160-164.

3. AZEVEDO MAO e FILHO GA. Competitividade e inclusão social por meio do esporte. Revista Brasileira ciência esporte. 2011, 33: 589-603.

4. BOERI ZA. Educação na promoção da saúde bucal. Dissertação (especialização em atenção básica) - Universidade Federal de Minas Gerais, Minas Gerais, 2013; 25p.

5. BRITO SR, et al. Gravidez na adolescência e associação com indicadores de renda, educação e acesso às tecnologias de informação e comunicação no Brasil e na Amazônia Legal Brasileira. Rio Grande do Sul. Revista de saúde e desenvolvimento humano. 2016,4(2): 21-33.

6. BUSS PM. Promoção da saúde da família; Rev. Bras. de saúde da família. 2002, 7: 50-63.

7. CARVALHO EFF e BRAGA PET. O jogo de tabuleiro como uma estratégia auxiliadora para o ensino de Zoologia, com s para as serpentes. Ensino, Saúde e Ambiente, 2013; 6(3): 202-217.

8. COMPARINI IP. Indicadores emocionais no desenho e dificuldades comportamentais em crianças, SP. Dissertação (mestrado em psicologia) - Centro de ciências da vida-PUC Campinas. São Paulo, 2016; 139p.

9. FADEL CB, et al. A educação como prática viabilizadora da saúde bucal. São Paulo, Rev. J Health Sci Inst., 2013, 31(2): 136-140.

10. GEHLEN SM. Jogos de tabuleiro uma forma lúdica de ensinar e aprender. Paraná. Secretaria de estado da educação. Superintendência da educação. Os desafios da escola publicam paranaense na perspectiva do professor pde, Curitiba: seed/pr,2013; 30p.

11. KUSMA SZ, et al. Promoção de saúde: perspectivas avaliativas para saúde bucal na atenção primária em saúde. Rio grande do sul. Cad. Saúde Pública. 2012, 18: 9-19.

12. MIRANDA TG e GALVÃO TA. O Professor e a educação inclusiva: formação, práticas e lugares. Bahia: EDUFBA. 2012; 497p.

13. OLIVEIRA RC. Vulnerabilidade social e juventude: um estudo de suas dimensões e seus impactos. VIII Jornada internacional de políticas públicas. 2017, 1-12.

14. OLIVEIRA VLS. A contribuição das atividades lúdicas na diminuição da violência escolar. Governo do Estado do Paraná, 2011;22p.

15. PAULETO, ARC et al. Saúde bucal: uma revisão clínica sobre programações educativas para escolares. Ciência e saúde coletiva, Rio de janeiro, 2004, 9(1):121-130.

16. PASSAMAI MPB, et al. Letramento funcional em saúde: reflexões e conceitos sobre seu impacto na interação entre usuários, profissionais e sistema de saúde. Interface - Comunic., Saude, Educ. 2012; 16(41): 301-314.

17. PASTORE GU, et al. Odontologia do esporte uma proposta inovadora. Ver. Bras Med Esporte, São Paulo, 2017, 23(2): 147-151.

18. PRADO LL. Jogos de tabuleiro modernos como ferramenta pedagógica: pandemic e o ensino de ciências. Ver. Eletronica ludus scientiae. 2018, 2(2): 26-38.

19. RAUL MCTD. A ludicidade na educação: uma atitude pedagógica. Curitiba: Intersaberes, 2007; 248p.

20. RODRIGUES HA, et al. O esporte coletivo no contexto dos projetos esportivos de inclusão social: contribuições a partir do referencial técnico-tático e sócio-educativo. Goiânia, Revista Pensar a prática, 2013, 16:320-339.

21. RODRIGUES DA, et al. Práticas educativas em saúde: o lúdico ensinando a saúde para a vida. Joao Pessoa, Rev. Ciência e saúde nova esperança, 2015, 13(1): 84-89.

22. SALCI MA, et al. Educação em saúde e suas perspectivas teóricas: algumas reflexões. Florianópolis, Texto Contexto Enferm. 2013; 22(1): 224-30.

23. SEBOLD R, et al. Formação continuada de professores: espaço de ação- reflexão-ação da literacia para a saúde. Minas Gerais. Revista Família, Ciclos de Vida e Saúde no Contexto Social. 2017; 2: 1-14.

24. SILVA AMG e BONIS R. Odontologia desportiva: A influência da saúde bucal na performance dos atletas da vila olímpica de Manaus. Boletim informativo unimotrisaúde em sociogerentologia, Amazonas, 2018; 9: 79-91.

25. SILVA CGCO e CARDOSO FS. Lições sobre democracia e cidadania a partir da análise do movimento escola sem partido. Revista direito em debate, Rio Grande do Sul. 2018; 50: 164-182. 
26. SILVA NMA, et al. Relato de experiência didática sobre o uso dos jogos na construção de aprendizagem no conteúdo de biologia. João Pessoa. Anais do Congresso Nordestino de Biólogos - Congrebio. 2016; 6: 203-211.

27. SOUZA RHA, et al. Desenvolvimento de jogo eletrônico como intervenção de educação em saúde para o adolescente. Rio grande do Sul, CINTED-UFRGS, 2017; 15(1): 1-10.

28. TOMITA NE, et al. Educação em saúde bucal para adolescentes: uso de métodos participativos. rev. FOB, São Paulo, 2001, 9(1/2): 63-69.

29. TOSCANI NV, et at. Desenvolvimento e análise do jogo educativo para crianças visando á prevenção de doenças parasitológicas. São Paulo, Interface-comunic, saúde, educ. 2007; 11(22): 281-294.

30. TSUZUKI FM, et al. Prevalencia e severidade da carie dentaria em um município em condição de vulnerabilidade social no estado do Paraná. São Paulo, Arch health invest, 2018; 7(4): 129-133.

31. VIANNA JA e LOVISOLO HR. Projetos de inclusão social através do esporte: notas sobre a avaliação. Porto Alegre, rev. Movimento revista de educação física da UFGRS, 2009, 15: 4-16.

32. VIANNA JA, LOVISOLO HR. A inclusao social através do esporte: a percepcao dos educadores. São Paulo, Rev. Bras. Educ. Fis. Esporte. 2011; 25: 286-96. 